LiminaR. Estudios Sociales y Humanísticos

ISSN: 1665-8027

liminar.cesmeca@unicach.mx

Centro de Estudios Superiores de México y

Centro América

México

Kauffer-Michel, Edith Françoise

De las indefiniciones a las demarcaciones inacabadas: repensar las fronteras fluviales y terrestres entre México, Guatemala y Belice

LiminaR. Estudios Sociales y Humanísticos, vol. XI, núm. 2, julio-diciembre, 2013, pp. 70-81

Centro de Estudios Superiores de México y Centro América

San Cristóbal de las Casas, México

Disponible en: http://www.redalyc.org/articulo.oa?id=74527870005

- Cómo citar el artículo

- Número completo

- Más información del artículo

- Página de la revista en redalyc.org

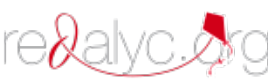

Sistema de Información Científica

Red de Revistas Científicas de América Latina, el Caribe, España y Portugal

Proyecto académico sin fines de lucro, desarrollado bajo la iniciativa de acceso abierto 


\title{
DE LAS INDEFINICIONES A LAS DEMARCACIONES INACABADAS: REPENSAR LAS Fronteras FluViales y Terrestres ENTRE MÉXICO, GuATEMALA Y BELICE
}

\author{
From a lack of definitions to unfinished demarcations: rethinking river and land borders between Mexico, \\ Guatemala and Belize
}

Edith Françoise Kauffer-Michel

Resumen: Las peculiares características de la definición de las fronteras fluviales entre México y sus vecinos del sur, Guatemala y Belice, así como la demarcación incompleta de las fronteras terrestres, todas establecidas en los tratados de límites de finales del siglo XIX, permiten difícilmente cumplir con una función tradicional de separación y marcación física de los límites de las soberanías. Ello pone en duda el carácter de límite de la división política establecida y nos obliga a repensar los conceptos para analizar estas fronteras paradójicas. A partir de un trabajo de campo reciente, esta contribución propone algunas pistas para el análisis de estas fronteras.

Palabras clave: fronteras, límite, tratados, demarcación, dualidades, acuerdos internacionales.

\begin{abstract}
The special characteristics of river borders between Mexico and its southern neighbours, Guatemala and Belize and the incomplete land borders' demarcation that were established by boundary treaties at the end of XIX century hardly allow to achieve the traditional border function as a limit of state sovereignty through separation and physical marks. This situation questions the limits and constrains by reconsidering the concepts to analyse this paradox about these borders. Based on recent fieldwork, he paper also tries to propose some suggestions for further studies.
\end{abstract}

Keywords: borders, limit, treaties, demarcation, dualities, frontier, boundary, international agreements.

\footnotetext{
Edith Françoise Kauffer Michel, doctora en Ciencias Políticas por el Instituto de Estudios Políticos de las Universidad de Aix-Marseille III, Francia. Profesora-investigadora del Centro de Investigaciones y Estudios Superiores en Antropología Social (CIESAS-Sureste). Temas de especialización: agua, políticas públicas, hidropolítica, frontera, relaciones internacionales, migraciones y género. Correo electrónico: ekauffer@ciesas.edu.mx, kauffer69@hotmail.com.

Enviado a dictamen: 31 de enero de 2013. Aprobación: 20 de abril de 2013.

Revisiones: 1.
} 
$\mathrm{H}$ oyen día, una partedelaliteratura especializada sugiere que las fronteras parecen ocupar un lugar menor como límites de soberanía en un contexto de multiplicación de las movilidades, de generalización de los intercambios (Weber, 2011: 116) y de incremento de las redes de comunicación. Así, se pueden distinguir las fronteras modernas o clásicas - aquellas de los Estados nacionales- de las posmodernas: éstas se materializan en un sistema económico globalizado como ejes de discriminación social y laboral. En este contexto, los conflictos en torno a las fronteras adoptan formas clásicas pero también tienden a transformarse.

Otra perspectiva actual de los "fronterólogos" subraya que las fronteras políticas están más que nunca presentes. Algunas cifras atestiguan su clara importancia en el mundo actual. Foucher (2007: 7) afirma que en un período de 15 años, entre 1991 y 2006, aproximadamente 26000 nuevos kilómetros de fronteras entre Estados nacionales fueron edificadas, mientras que en 24000 kilómetros se llegó a acuerdos de delimitación o demarcación. Además, 18000 kilómetros de barreras han sido imaginadas y en ellas se encuentran muros, cercas, bardas de metal o vallas electrónicas, aunque no todas se materializaron. Ello significa que de los 248000 kilómetros de fronteras existentes en el mundo, aproximadamente un 10\% son de creación reciente y otro porcentaje equivalente coincide con una demarcación realizada también en fechas cercanas. En términos de Foucher (2007: 7), "la producción continua de las fronteras políticas" en la actualidad tiende a universalizarse mediante una envoltura ${ }^{2}$ actualizada de los nuevos Estados con la finalidad de consolidar sus soberanías de forma tradicional o incluso de cerrar definitivamente el paso. En este contexto aparentemente contradictorio de reforzamiento de las fronteras políticas tradicionales y de desaparición de las mismas debido a los flujos de población, de mercancía y de información y a la conformación de bloques económicos regionales, hablar de las fronteras que México comparte con Guatemala y Belice resulta pertinente por varias razones.
En primer lugar, Basail (2005: 244) considera que existen ocho temas emergentes sobre la frontera sur. ${ }^{3}$ Entre éstos, el autor evoca el estudio de la vigencia de la frontera política demarcada por el Estado mexicano, aun cuando ello se manifiesta a la par de procesos económicos desterritorializados y de la existencia de fronteras culturales entrecruzadas. El análisis que proponemos a continuación se centra en esta perspectiva tradicional aunque poco estudiada en la actualidad para las fronteras que aquí se abordan.

En segundo lugar, varios fenómenos actuales observables en las fronteras de México con sus vecinos del sur resultan de interés para el análisis de las fronteras políticas. Por un lado, al igual que la aparente contradicción entre el desvanecimiento y el reforzamiento de las fronteras en el mundo, observamos una multiplicación de procesos que parecen poner en entredicho la existencia de una frontera política tradicional con fenómenos que podrían indicar justamente lo contrario. Por el otro, la multiplicidad de las otras fronteras concomitantes y entrecruzadas llama a reflexionar en torno a las problemáticas actuales de las fronteras internacionales.

En tercer lugar, el trabajo de campo y la revisión documental recientes acerca de las fronteras entre México y Guatemala, y México y Belice, invitan a presentar una serie de elementos empíricos relacionados con las circunstancias de estas fronteras límite que no son enunciados en otras publicaciones aún recientes sobre el tema (Castillo et al., 2006).

Partiendo de este último aspecto, esta contribución invita a repensar las fronteras límite, políticas y geopolíticas entre México y Guatemala y entre México y Belice: propone abandonar la visión homogénea y hegemónica de la unicidad de la frontera y plantea que se trata de dos fronteras porque, a pesar de obedecer a dos fenómenos cercanos en el tiempo desde su establecimiento, corresponden a procesos históricos diferenciados en sus formas de interacción y en sus realidades actuales. Para ello, este trabajo inicia con una discusión del concepto de frontera límite y de sus significados. Posteriormente, analiza las problemáticas actuales de las dos fronteras políticas encontradas 
durante el trabajo de campo y la revisión documental, las cuales no solamente dificultan el cumplimiento de su carácter de límite en el sentido tradicional de barrera, sino en su falta de continuidad e imprecisiones físicas. Finalmente, termina la reflexión con una invitación a una redefinición amplia del concepto de frontera política y a repensar estas fronteras a la luz de sus realidades actuales, de las herencias del pasado y de la complejidad de los fenómenos fronterizos y transfronterizos observados hoy en día en la región.

\section{La frontera límite: una aproximación teórica}

Consideramos fundamental iniciar esta reflexión con una revisión del significado de frontera límite, sus orígenes y sus relaciones con el territorio para entender mejor la problemática en las dos fronteras de México que se presenta más adelante.

Al comparar el término frontera en inglés con sus sinónimos en alemán, francés, español o italiano, y al analizar sus relaciones con el latín, Rankin y Schoefield (2004: 5) nos muestran una terminología muy amplia en inglés y mucho más reducida en castellano. A los tres términos anglosajones de border, frontier, boundary ${ }^{4}$ corresponde la polisémica noción de frontera. La primera, la frontera conocida como border, se refiere a la línea de división, delimitación y demarcación política, es decir, la frontera geopolítica también conocida como frontera tradicional a la cual llamaremos frontera límite. Se ubica en el centro del análisis presentado en este trabajo y como punto de partida del mismo.

Por su parte, la frontier se relaciona con los procesos de colonización, de dominación del espacio mediante el avance del poblamiento humano en un territorio determinado. Fue acotado como concepto a raíz de la conquista del Oeste estadounidense y fue acuñado por Turner (1793).

Ambos conceptos han sido fundamentales para el análisis de la frontera de México con sus vecinos del sur ya que han sido el soporte teórico de los trabajos de Jan de Vos (1993, 2002, 2010), de Andrés Fábregas (2009) y de Fábregas y Román (1994) en la región. Fueron retomados por otros autores (Blanco,
2012; Chavarochette, 2011; Kauffer, 2002, 2005, 2010) para analizar diversos fenómenos de estas fronteras poco estudiadas y reconocidas como tales hasta hace aproximadamente 20 años.

La border o frontera límite es considerada como una "frontera rígida" (Ortega, 2012: 43) o "geopolíticamente al puro estilo europeo" (Ortega, 2012: 17), es decir, una frontera derivada de la formación de los Estados nacionales surgidos en aquel continente. En este sentido, una frontera es, en palabras de Weber (2011), un "prisma de difracción de las apuestas territoriales" y, según Foucher (2007: 21), las fronteras constituyen "discontinuidades territoriales con funciones de marcaje político."

Así, una frontera límite es mucho más que una simple línea de separación, la cual en la realidad puede a veces convertirse en barrera o resultar bastante permeable, y se relaciona además con el territorio, la autoridad y el poder.

Plantear la frontera como un "límite político significante de un territorio" (Groupe Frontière, 2004) implica que cualquier territorio en construcción integra los elementos de una frontera. En consecuencia, más allá de una línea de separación, una frontera constituye un objeto establecido por un poder político que busca afirmarse y diferenciarse de otro poder mediante la delimitación de un territorio donde ejerce autoridad, de tal forma que, como afirma Foucher (2007: 8), una frontera es también una envoltura externa. Ello implica entonces que la frontera límite posee una doble función: la primera hacia fuera, como barrera y separación, y la segunda hacia dentro.

Diversos autores (Groupe Frontière, 2004) hacen referencia a Renard, para quien la frontera representa el punto culminante de una gradación conceptual: se trata de una "separación estructurante que expresa o revela el ejercicio de un poder", la cual incluye una discontinuidad entre estructuras espaciales de organización y que se suma también al límite, es decir, lo que marca la diferencia entre dos conjuntos espaciales.

Partiendo de esta dualidad de la frontera como un fenómeno ubicado entre una abstracción cartográfica y una concreción, Brenna (2010: 270) subraya que las 
fronteras nacionales presentan otra dualidad: son a la vez delimitaciones geopolíticas de los Estados nacionales - es decir, desempeñan una función hacia fuera- y espacios de exclusión y protección - preservan el conjunto que se encuentra en el interior de la frontera en tanto "envoltura", como menciona Foucher-.

Así, la frontera política es una "construcción territorial que establece distancia en la proximidad" (Groupe Frontière, 2004). Cuatro funciones se derivan de esta definición, entre las cuales aquella de distanciación es fundamental y se traduce en la construcción de elementos materiales, normativos o simbólicos. La segunda función de una frontera es su papel como sistema de control de los flujos de personas y de mercancías, control del territorio que se establece mediante un filtro que puede adoptar modalidades selectivas.

Las dos funciones adicionales de una frontera se relacionan con aspectos claramente políticos. Así, se plantea como un "lugar privilegiado de afirmación y reconocimiento de los poderes políticos" (Groupe Frontière, 2004: 4) por la definición o imposición de un límite en tanto expresión de una separación política: dicha función es aún más clara en caso de litigios, conflictos y negociaciones. Finalmente, al establecer una distinción entre dos entidades territoriales, una frontera define una alteridad a partir de una distinción mediante aspectos a la vez materiales y simbólicos.

Entre los efectos de las fronteras se encuentra la creación de "sistemas espaciales singulares" a partir de las rupturas que ésta establece en el espacio; una serie de diferenciaciones además de la definición de un "espacio de riesgos" y de "lugares de hibridación" (Groupe Frontière, 2004: 5). Los dos primeros se derivan de las funciones separadoras de las fronteras y los últimos de su carácter de lugares de relación que pueden generar conflictos, y por ende riesgos, o bien favorecer diversos tipos de interacciones.

\section{Paradojas del límite en la doble frontera}

Lejos de aparecer como telón de acero, límite infranqueable o barrera que controla, las fronteras que
México comparte con Guatemala y Belice han sido señaladas como porosas y permeables en comparación con aquella que México posee con Estados Unidos. Las características naturales del área, así como la continuidad de los recursos naturales y la ubicación de la frontera en zonas alejadas, poco pobladas y difícilmente accesibles, favorecen esta permeabilidad. Las dinámicas socioculturales contribuyen también a la porosidad: la existencia de un continuum cultural, en particular entre grupos indígenas que se extienden más allá de la delimitación internacional, los constantes flujos de personas, las mercancías de todo tipo que entran y salen, las relaciones de parentesco establecidas entre pobladores ubicados en ambos lados del límite y los intercambios transfronterizos de bienes y servicios.

Así, varios elementos de esta frontera límite presentan más las características de un espacio de acercamiento y de interacciones que un escenario de diferenciación o un sistema de control, de filtro o de distanciamiento. Dicha situación se refleja en particular en la ausencia de marcadores físicos que visibilizan y cierran estas fronteras y en la escasa presencia de puntos oficiales de cruce. ${ }^{5}$ En consecuencia, este conjunto de factores contribuye a la permeabilidad de esta doble frontera, a los que se suman los problemas de demarcación, los cuales presentan una serie de paradojas que llevan a cuestionar su carácter de límite. Éstos se observan a la vez en el caso de las fronteras fluviales y terrestres.

\section{Las indefiniciones de las fronteras fluviales}

Más de la mitad de la frontera entre México y Guatemala (53\%) es fluvial y corresponde a los ríos Suchiate y Usumacinta. ${ }^{6}$ El primero, de 92 kilómetros de longitud, nace en Guatemala y desemboca en el Océano Pacífico después de marcar 77 kilómetros de frontera. El segundo, que se abastece de varios tributarios con orígenes en cuencas guatemaltecas, como los ríos Chixoy y San Pedro, marca 365 kilómetros de frontera internacional entre el estado de Chiapas y Guatemala, de un curso total de 1114 kilómetros, antes de fluir hacia el Golfo de México por el estado de Tabasco. 
La mayor parte de la frontera entre México y Belice (86\%) es fluvial y corresponde al río Hondo y ésta mide, tomando en cuenta el límite correspondiente al arroyo Azul que nace en el norte de Guatemala, sumado al río Hondo, un total de 160 kilómetros.

Ambas fronteras fluviales corresponden a tratados de límites negociados y firmados a finales del siglo XIX: el primero en 1882 entre México y Guatemala, y el segundo en 1893, entre México y Honduras Británica, colonia inglesa de la cual surge en 1981 el Estado independiente de Belice, con el cual no existe en la actualidad un tratado de límites.

El uso de elementos de la naturaleza como ríos, montañas y parteaguas como fronteras deriva de la extrapolación de la separación que los océanos representaron en su momento como las fronteras "naturales" por excelencia.

La noción de fronteras naturales nace en la Edad Media y fue clave durante los siglos XVIII y XIX (Rankin y Schoefield, 2004: 7; Shaffter et al., 2009). La cuestión de los límites naturales es particularmente sostenida en diferentes épocas por Francia y su aparición puede ubicarse en el año 843, cuando los tres nietos de Carlomagno se distribuyeron el Imperio y utilizaron dos ríos para establecer los límites territoriales: los ríos Meuse y Rin (Pounds, 1951: 149). El río Rin es posteriormente, durante el siglo XVI, defendido por Francia en contra del Imperio Germánico (Pounds, 1951: 155-156). A partir del siglo XVIII, los filósofos de las luces adoptan una justificación sustentada en la defensa de su territorio derivada de las leyes de la naturaleza y de la razón para determinar el orden político y las fronteras del territorio (Pounds, 1954: 53). Las fronteras naturales de Francia aparecen entonces como el Océano Atlántico, el río Rin - frontera actual con Alemaniay las cadenas montañosas de los Pirineos - frontera con España- y de los Alpes - frontera con Italia-, de tal forma que al final del siglo XIX el destino político de Francia parece inscrito en la geografía (Pounds, 1951: 146). La frontera natural entonces aparece de orden casi divino, es legítima e incuestionable. Las llamadas fronteras naturales son planteadas como indelebles porque son definidas por la naturaleza, además de poseer una concreción material que las hace reales debido a su inscripción en la geografía y a su visibilidad. Desde este punto de vista, todas las otras fronteras son artificiales, arbitrarias y temporales (Rankin y Schoefield, 2004: 7).

En el caso de las fronteras de México que nos interesan, la noción resulta relevante porque la frontera fluvial de los tres ríos obedece al thalweg, también llamado canal más profundo del río. El thalweg es un sistema de demarcación de fronteras fluviales utilizado durante el siglo XIX en los ríos europeos caudalosos y navegables y se fundamenta en un acceso equitativo a la navegación, que era su principal función en aquella época.

La problemática que el thalweg presenta para los ríos con importantes fluctuaciones en su caudal reside en que, al aumentar o disminuir el volumen de agua, el thalweg tiende a moverse a lo largo del año, e incluso año tras año, en función del volumen de las precipitaciones. Éste es en particular el caso del río Suchiate, donde el caudal se puede multiplicar por diez durante la temporada de lluvia, cuando la corriente erosiona márgenes y produce inundaciones. Esta situación provoca una movilidad del canal más profundo del río, y por ende de la frontera fluvial, lo cual ha sido señalado en varios estudios (Kauffer, 2011; Santacruz, 2011).

En el río Hondo, la situación del thalweg se plantea de manera inversa al Suchiate y se torna problemática durante la época de estiaje. En la parte alta de la cuenca que corresponde al arroyo Azul, la reducción del caudal es tal que el río desaparece y la ubicación del thalweg resulta imposible de realizar durante esta época del año dado que la frontera fluvial desaparece por evaporación.

\begin{abstract}
Además, se encontró que el Arroyo Azul no cruza el meridiano del Salto de Garbutt, como se indica en el tratado, sino que en su parte alta se forma una gran llanura de inundación sin cauce definido que, en época de secas, desaparece (Auditoría Superior de la Federación, 2007: 398).
\end{abstract}

Más allá de su legitimidad fundamentada en una voluntad superior, de origen divino o humano como la 
razón, ${ }^{7}$ se supone que el uso de la naturaleza para fijar fronteras es no solamente más sencillo como marcador antes de la existencia de los sistemas de información geográfica y de las fotografías aéreas y satelitales, sino fijo y definitivo. Pero, en realidad, las propias contradicciones del thalweg evidenciadas en el caso de las fronteras sureñas de México permiten afirmar que la definición de una frontera a partir de un río no resulta tan sencilla. De hecho, implica un criterio de delimitación, el cual, lejos de ser natural, obedece a una decisión política: el criterio puede ser terrestre, es decir, ubicarse en alguna de las dos riberas del río, o bien en la corriente, como es el caso del thalweg o del canal mediano del río. Así, en su concreción, la fijación de una frontera fundamentada en un elemento de la naturaleza constituye un acto político, negociado y convencional, y refleja el carácter relacional de la frontera en un lugar y tiempo determinados (Raffestin, 1986: 9). A este respecto, cuando la delimitación se establece en un margen, significa la exclusión del goce del río por el Estado ubicado más allá de la línea divisoria, es decir, que esta decisión sugiere una situación de desigualdad mientras que el criterio de thalweg, en lo que refiere a navegación, refleja una relación menos asimétrica. El caso de la adopción del thalweg para las fronteras de México se relaciona también con su vigencia como criterio de demarcación en la época de firma de los tratados de delimitación.

La gran contradicción de las llamadas fronteras naturales reside entonces en el hecho de que, si bien siguen elementos de la naturaleza, corresponden en realidad a negociaciones políticas. Así, todas las fronteras son intencionales, derivan de una voluntad y nunca son arbitrarias. Algunas se legitiman mediante un rito religioso y posteriormente mediante un acto político (Raffestin, 1986: 3). De todas formas, son políticas, independientemente de que hayan sido negociadas entre los pueblos o establecidas por las élites gobernantes.

Las fronteras fluviales de los ríos Suchiate y Hondo evidencian que, lejos de garantizar una estabilidad a través de los siglos, el establecimiento de fronteras llamadas naturales en ríos con las características antes mencionadas contribuye a volver paradójicos e inciertos los límites internacionales así definidos. Dicha definición se inscribe en un contexto histórico y político peculiar que es determinante para entender su lógica, aunque a través del tiempo se pueda convertir en un elemento inoperante como las fronteras antes mencionadas lo indican.

\section{Las paradojas de las fronteras terrestres: de la definición a la demarcación}

Tres fases llevan a la fijación de una frontera: la definición, la delimitación y la demarcación (Raffestin, 1986: 10). Para el caso que nos interesa, el primer momento se refiere al proceso de negociación diplomática cuyo resultado fueron los dos tratados de límites antes mencionados. Los tratados son más o menos precisos y, por lo general, sobre todo cuando fueron firmados más de un siglo atrás, permiten observar una gran diferencia entre el texto y la realidad in situ. La segunda fase del establecimiento de una frontera límite corresponde a la delimitación: se trata de la labor de plasmar la decisión política en los mapas de la forma más precisa posible. Hoy en día, las tecnologías de información geográfica y de comunicación hacen más sencillo este paso, el cual anteriormente resultaba mucho más complejo.

Finalmente, la tercera fase se traduce en la demarcación de la frontera, es decir, la concreción de las etapas anteriores en campo mediante puntos fijos del paisaje - por ejemplo, elementos naturales del mismo - o marcadores físicos, tales como monumentos, morones o piedras. Raffestin (1986: 10) considera que lo crucial de esta fase es hacer "coincidir mapa y territorio, 'representación' y 'representado".

Es importante mencionar que entre las tres fases pueden transcurrir años, décadas o incluso siglos. En particular, sobre todo para el caso de las fronteras definidas y delimitadas en el pasado y aún no demarcadas in situ, esta última fase puede tardar porque es susceptible de generar conflictos derivados de las imprecisiones e incertidumbres. Por ejemplo, en fechas recientes Francia propuso adoptar un sistema geodésico común para terminar de demarcar sus fronteras con 
sus siete vecinos (Bacchus, 2006). En efecto, para garantizar el carácter de límite de una frontera es necesaria una demarcación clara y precisa debido a que ésta es "un factor de orden, de estabilización y de regulación" (Raffestin, 1986: 11). Además, la precisión de la demarcación se traduce en un menor surgimiento de conflictos.

Para el caso que nos interesa hemos evidenciado el carácter móvil de una parte de la frontera fluvial del río Suchiate y la situación inestable de la frontera del río Hondo debido a su evaporación estacional en la parte alta de su cuenca. Con respecto a las líneas terrestres entre México y Belice, y entre México y Guatemala, encontramos problemas derivados de una inexistencia de demarcación de la primera relacionada con la problemática de una definición y una delimitación que están desfasadas con las condiciones políticas actuales, a lo cual se suma una demarcación inconclusa de la línea divisoria entre México y Guatemala.

Se mencionaba párrafos arriba la mala ubicación del arroyo Azul con respecto al meridiano del Salto de Garbutt, constatada durante una visita de campo por parte de la Auditoría Superior de la Federación en 2007; es decir, no existe una adecuada coincidencia entre la definición de la frontera plasmada en el tratado entre México y Honduras Británica y su existencia en el territorio real como consecuencia de la delimitación de la misma.

De lo anterior, se concluye que el Tratado sobre Límites entre México y Honduras Británica estableció los límites entre las dos naciones, y no se definieron compromisos para el trazado, señalización y conservación de los límites entre ambos países, y que existen diferencias entre las coordenadas geográficas incluidas en el tratado y la ubicación física de los límites naturales establecidos (Auditoría Superior de la Federación, 2007: 398).

Este fragmento precisa que, después de más de un siglo de tratado, la labor de demarcación de la frontera terrestre entre México y Belice no ha iniciado aún. Finalmente, la misma fuente subraya los distintos esfuerzos encaminados a la firma de un nuevo tratado que aún no se han logrado concretar. De hecho, el problema de fijación de la frontera común incluye también inexactitudes relacionadas con la frontera en la Bahía de Chetumal que han propiciado conflictos en torno a la frontera marítima. En realidad, el logro de una futura demarcación dependerá sin duda de un proceso diplomático largo que permita sentar las bases de una definición jurídica actualizada de la frontera límite entre México y Belice.

En el caso de la frontera entre México y Guatemala, nos encontramos en este momento en la difícil fase de demarcación de la frontera límite sobre la base de una delimitación conflictiva que dejó secuelas en parte de la sociedad guatemalteca y en una élite que todavía reclama el carácter injusto y desfavorable del establecimiento del límite internacional (De la Torre y Cabrera, 2008). ${ }^{8}$ De hecho, la fase de demarcación inició formalmente a partir de la creación de la Comisión Internacional de Límites y Aguas (CILA) México-Guatemala en 1961, pero se intensificó únicamente después de la firma en 1990 y de la posterior ratificación en 2003 del tratado de fortalecimiento de dicha Comisión. La demarcación que constituye una de las principales funciones de la CILA se aboca a dos acciones (CILA, 2006): la elaboración de una brecha, es decir, una línea de diez metros de ancho, cinco a cada lado de la ubicación del trazo de la línea internacional que cubre toda la longitud de la frontera terrestre, acompañada de la renovación y de la construcción de monumentos principales e intermedios. Al iniciar las actividades de demarcación in situ, éstos se encontraban a distancias variables, entre 55 metros y 14 kilómetros (CILA, 2006), cuando el tratado de 1882 estipula en su artículo IV que deben ser visibles uno con respecto al otro. En el año 1941 fue elaborada una lista de 107 monumentos principales a construir en la frontera mexicano-guatemalteca tal como lo establece el artículo VI del tratado de límites y el protocolo de 1883 (ASF, 2007: 379-381). Entre 1994 y 2007 fueron construidos 1673 monumentos intermedios, de los cuales 76 no fueron reconocidos por Guatemala, en una franja de 305 kilómetros ubicada entre el estado 
de Tabasco y el norte de Guatemala. El rechazo a reconocer estos monumentos se relaciona con el hecho de que en esta parte del trazo Guatemala se opone a la demarcación de la frontera que depende de 42 monumentos principales, y pide desde 2005 la rectificación de su ubicación. Por ende, objeta así la delimitación de la frontera considerada por su vecino. México establece que la posición de los monumentos es correcta porque obedece a los medios utilizados cuando se realizó la definición de la frontera límite entre ambos países en años posteriores a la firma del tratado de límites. Esta situación ilustra entonces la dificultad relacionada con una demarcación posterior a las tareas de definición y delimitación, y con la transformación de los instrumentos de delimitación.

Así, el conflicto acerca de la demarcación de la frontera entre México y Guatemala se relaciona por un lado con la delimitación realizada en décadas anteriores y su no coincidencia con aquélla hecha con los instrumentos utilizados hoy en día para esta misma finalidad, punto observado por la Auditoría Superior de la Federación en 2007.

Asimismo, con la revisión del informe elaborado por el Instituto Nacional de Estadística, Geografía e Informática y la Sección Mexicana de las Comisiones Internacionales de Límites y Aguas México-Guatemalay México-Belice en 2003 sobre la posición geodésica de los 107 monumentos limítrofes internacionales principales que definen la línea divisoria internacional terrestre entre México y Guatemala, la Auditoría Superior de la Federación constató que el sistema de coordenadas geográficas - geocéntricas, no geodésicas-, así como las orientaciones astronómicas realizadas para localizar los sitios de monumentos principales en el siglo XIX y la precisión del instrumental usado en esa época, no permiten realizar una comparación directa con los resultados de coordenadas geográficas obtenidas por posicionamiento geodésico satelital del tipo global positioning system (GPS) en los mismos puntos debido a que son sistemas de medición diferentes (ASF, 2007: 382).

En consecuencia, mientras México sostiene una demarcación acorde a lo que entiende por definición de la frontera en el tratado mediante la delimitación histórica, Guatemala rechaza una demarcación que se fundamenta en una delimitación que no le favorece. El origen aparente del problema se ubica entonces en un asunto de delimitación, es decir, en la forma de plasmar la definición establecida en el tratado en los mapas de ambos países y se concreta en tensiones en materia de demarcación. Jan de Vos (1993: 10) menciona a este respecto las numerosas imprecisiones de la delimitación histórica de la frontera mexicano-guatemalteca.

La demarcación de las fronteras terrestres que México comparte con Guatemala y Belice es todavía hoy en día, más de un siglo después de la firma del tratado de límites, un proceso incompleto. En el caso de Guatemala, a pesar de haber iniciado, los conflictos en torno a esta fase del establecimiento de la frontera llevan al replanteamiento de la fase de delimitación. En la interacción con Belice, la ausencia de demarcación está relacionada con la necesidad de una nueva definición de esta frontera con el Estado nacional que se formó a finales del siglo XX, es decir, un tratado de límites entre México y Belice.

Con respecto a las fronteras fluviales, el criterio de delimitación medianteel thalweg dificulta adicionalmente una fijación definitiva de una frontera que tiende a moverse en el río Suchiate y a evaporarse en el río Hondo y complica la demarcación de la línea. En estos últimos casos, la definición de las fronteras establecidas por los tratados repercute en una delimitación que impide fijar la frontera política y hace imposible la tarea de demarcación. Así, las fronteras límite del sur de México constituyen una realidad que aún no termina de establecerse de forma definitiva y fija en su dimensión fluvial, y mucho menos en su aspecto terrestre, lo cual las convierte en fronteras paradojas.

\section{Conclusiones: repensar las fronteras límite}

Al término de esta contribución, podemos afirmar que las fronteras entre México, Guatemala y Belice poseen poca concreción en la práctica como límites y por lo tanto presentan una serie de paradojas en su dimensión de envoltura, de límite y en su función de control. Sin embargo, los Estados nacionales las defienden, los 
pobladores que viven en ambos lados las mencionan y la diferenciación es una realidad que se observa, por ejemplo, en las actividades cotidianas, así como en la intensidad de los flujos de personas y mercancías. Aun con sus imprecisiones, estas fronteras existen.

Las fronteras, como lo indica Foucher (1991: 38), se ubican en tres registros: la realidad del trazo físico, lo simbólico de la pertenencia a una identidad y lo imaginario con la alteridad y la historia propia. Hasta el momento, este texto se ha centrado en el primero. En las líneas que siguen pretendemos esbozar algunas ideas para complejizar la mirada y repensar las fronteras límite.

Para superar las paradojas mencionadas, y tomando en cuenta lo sugerido por Foucher, esta reflexión podría ser completada más adelante si conceptualizamos las fronteras políticas como conjuntos de dualidades encadenadas debido a lo siguiente: a la primera dualidad de las fronteras como barreras y líneas de separación versus la dimensión de contactos que favorecen, se suma una segunda que opone el límite como marcador y el espacio de ejercicio del poder de la cual se deriva el doble significado de las fronteras, hacia afuera y hacia adentro. A esta primera dualidad encadenada se suman los procesos actuales de desaparición-reforzamiento de su presencia observable a través de diferentes ejemplos en el escenario internacional.

Ante esta complejidad de procesos duales encadenados podemos aprehender los fenómenos observados, como lo sugiere Brenna (2010: 273), en una continuidad espacial específica: "la frontera no se crea ni se destruye, sólo se transforma." Así, las fronteras nacionales, límites, políticas o geopolíticas adquieren flexibilidad en sus funciones de separación y de contacto. En consecuencia, se vuelven más exclusivas mediante la creación de nuevas desigualdades (Brenna 2010: 273).

Finalmente, una de las dualidades no solamente materiales, sino también conceptuales, que pueden permitir repensar estas fronteras límite es la relación con las otras fronteras, en particular la frontier. Jan de Vos (2010: 31) evoca esta relación: "la férrea frontera límite, inmóvil y nítida, que divide drásticamente en dos un territorio o grupo étnico, y la no menos poderosa frontera-frente, móvil y dinámica ésta, que permite a personas o comunidades humanas crear espacios sobre los cuales después deciden avanzar o retroceder". Andrés Fábregas (2009: 54), por su parte, subraya la demarcación de la frontera nacional política mediante la frontera de expansión según Turner, donde los procesos locales y nacionales entrelazados plantean la frontera desde una doble perspectiva: la política y la cultural (Fábregas, 2009: 55).

Finalmente, repensar la frontera límite implica también analizar no solamente con más profundidad la relación entre estas dos fronteras, sino con todas las otras fronteras, en el sentido de boundaries: las fronteras sociales, culturales y étnicas que se yuxtaponen, refuerzan los procesos antes descritos y contribuyen en particular a alimentar las fronteras como conjuntos de dualidades encadenadas en los registros reales, simbólicos e imaginarios de los diferentes actores que intervienen en sus definiciones: hacia adentro y hacia afuera, en la separación y en las interacciones, y sobre todo como marcadores en su relación con la definición de espacios de ejercicio del poder.

\section{Notas}

1 Agrupamos en esta denominación a las personas que realizan investigaciones acerca de las fronteras, independientemente de su disciplina del conocimiento científico.

${ }^{2}$ Esta idea será retomada y profundizada más adelante.

3 A diferencia de la denominación generalizada de "frontera sur" de México, preferimos hablar de frontera entre México, Guatemala y Belice por dos razones. En primer lugar, porque la denominación de frontera sur homogeneíza no solamente las dinámicas locales, sino la realidad de la relación de México con Guatemala y de México con Belice cuando éstas son muy distintas en términos históricos y políticos. En segundo lugar, porque hablar de "frontera sur" es utilizar una visión hegemónica mexicana de la misma - para los guatemaltecos se trata de la frontera norte o noroccidental y para Belice es también la frontera 
norte- y enfocada en la relación entre Chiapas y Guatemala, donde se han concentrado la mayoría de los estudios. Finalmente, esta noción invita poco a mirar lo que pasa del otro lado porque está definida desde el centro hacia el contorno.

${ }^{4}$ Esta noción no será abordada en esta contribución, ya que ha sido poco estudiada, aun para las fronteras estudiadas.

5 A lo largo de más de 1000 kilómetros de frontera se encuentran nueve puntos de internación en Chiapas, dos en Tabasco, ninguno en Campeche y dos en Quintana Roo (INM, 2013) que se ubican en la línea de división internacional.

${ }^{6}$ Las cifras presentadas en este apartado son el producto de un ejercicio realizado a partir de un sistema de información geográfica en el cual medimos las fronteras terrestre, fluvial y los ríos internacionales —es decir, aquellos que forman la frontera-. Cabe subrayar que las cifras que presentan los académicos no se corresponden totalmente con las oficiales. La Comisión Internacional de Límites y Aguas (2006) y la Auditoría Superior de la Federación (2007) hablan de 959.6 kilómetros de frontera entre México y Guatemala y de 266 con Belice, es decir, un total de 1225.6 kilómetros. Por su parte, las fuentes académicas, como Castillo et al. (2006) y Kauffer (2010), hablan de 956 kilómetros con Guatemala y de 193 con Belice.

7 Cabe subrayar que la noción de frontera natural, después de ubicarse en orígenes divinos, se relacionó con la razón al ser adoptada por los filósofos de la Ilustración.

${ }^{8}$ La anexión de Chiapas y del Soconusco a México constituye el principal punto de inconformidad de Guatemala. Cabe subrayar que en el tratado de límites de 1882 Guatemala renuncia a sus reivindicaciones sobre Chiapas y el Soconusco. También tienden a causar controversias las compensaciones derivadas del tratado de límites, las cuales fundamentaron la demarcación definitiva de la frontera a partir de intercambios mutuos de tierras ubicadas en ambos lados de la frontera. En términos generales, Guatemala perdió tierras bien ubicadas y pobladas, y recibió áreas periféricas.

\section{Bibliografía}

Auditoría Superior de la Federación (ASF) (2007), Informe del resultado de la revisión y fiscalización superior de la cuenta pública 2007, Sector Gobernación, Sector Relaciones Exteriores, t. II, vol. 2, México: Auditoría Superior de la Federación.

Bacchus, Michel (2006), The maintenance of boundary pillars and boundary lines in France, International Symposium on Land and River Boundaries Demarcation and Maintenance of Borderland Development, Bangkok, Tailandia, 6-11 de noviembre.

Basail Rodríguez, Alain (2005), "Sobremesa”, en Alaín Basail Rodríguez (coord.), Fronteras des-bordadas. Ensayos sobre la frontera sur de México, México: Casa Juan Pablos/Universidad de Ciencias y Artes de Chiapas, pp. 239-246.

Blanco Abellán, Blanca (2012), No me puedo dejar: negociación y resistencia en el empleo doméstico. Aproximación a la capacidad de agencia de las empleadas domésticas guatemaltecas en Tapachula, Chiapas, (tesis de maestría en Antropología Social), Centro de Investigaciones y Estudios Superiores en Antropología Social, San Cristóbal de Las Casas, Chiapas.

Brenna, Jorge E. (2010), "De la frontera nacional a la frontera pluricultural”, en Frontera Norte, vol 22, núm. 44, Tijuana: El Colegio de la Frontera Norte, pp. 265 276.

Castillo, Manuel Ángel, Cecilia Toussaint Ribot y Mario Vázquez Olivera (2006), Espacios diversos, historia en común. México, Guatemala y Belice. La construcción de una frontera, México: Secretaría de Relaciones Exteriores. Chavarochette, Carine (2011), Frontières et identités en terres mayas. Mexique-Guatemala (XIXe-XXIe siècle), París: L'Harmattan.

Comisión Internacional de Límites y Aguas. Sección Mexicana (CILA) (2006), Land Demarcation between Mexico and Guatemala and Protection Works in the Suchiate River, International Symposium on Land and River Boundaries Demarcation and Maintenance of Borderland Development, Bangkok, Tailandia, 6-1l de noviembre. 
De la Torre, Armando y José Luis Cabrera (2008), Las fronteras disputadas entre México y Guatemala, Guatemala: Universidad Francisco Marroquín, 〈http://newmedia. ufm.edu/gsm/index.php/Las_disputadas_fronteras> [3 de marzo de 2012].

De Vos, Jan (1993), Las fronteras de la frontera sur. Reseña de los proyectos de expansión que figuraron la frontera entre México y Centroamérica, México: Universidad Juárez Autónoma de Tabasco/Centro de Investigaciones y Estudios Superiores en Antropología Social.

De Vos, Jan (2002), Una tierra para sembrar sueños. Historia reciente de la Selva Lacandona, 1950-2000, México: Centro de Investigaciones y Estudios Superiores en Antropología Social/Fondo de Cultura Económica.

De Vos, Jan (2010), Camino del Mayab. Cinco incursiones en el pasado de Chiapas, México: Centro de Investigaciones y Estudios Superiores en Antropología Social.

Fábregas Puig, Andrés (2009), "La frontera sur MéxicoGuatemala y la formación del Estado nacional. Una mirada antropológica”, en Jorge Ramón González Ponciano y Miguel Lisbona Guillén (coords.), Méxicoy Guatemala. Entre el liberalismo y la democracia multicultural, México: Universidad Nacional Autónoma de México, pp. 51-59.

Fábregas Puig, Andrés y Carlos Román García (1994), Al fin del milenio: el rostro de la frontera sur, Tuxtla Gutiérrez, Chiapas: Gobierno del Estado de Chiapas/Instituto Chiapaneco de Cultura.

Foucher, Michel (2007), L'obsession des frontières, París: Perrin.

Groupe Frontière (2004), La frontière, un objet spatial en mutation, Dictionnaire de le géographie et de l'espace des sociétés, 〈http://test.espacestemps.net/articles/lafrontiere-un-objet-spatial-en-mutation/> [6 de enero de 2013].

Instituto Nacional de Migración (INM) (2013), Listado de puntos de internación del INM, 〈http://www.inm. gob.mx/static/pago_derechos/catalogos_DPA/ Catalogo_Puntos_Internacion_2011.pdf $\quad\left[\begin{array}{ll}8 & \text { de }\end{array}\right.$ enero de 2013].

Kauffer Michel, Edith F. (2002), "Movimientos forzosos en la frontera sur. Una visión comparativa de los refugiados guatemaltecos en el sureste mexicano", en Edith F. Kauffer Michel (ed.), Identidades, migraciones y género en la frontera sur de México, México: El Colegio de la Frontera Sur, pp. 215-242.

Kauffer Michel, Edith F. (2005) "De la frontera política a las fronteras étnicas: refugiados guatemaltecos en México", en Frontera Norte, núm. 17, julio-diciembre, pp. 7-36.

Kauffer Michel, Edith F. (2010), "Migraciones y agua en la frontera entre México, Guatemala y Belice: aproximaciones en torno a una relación multiforme", en LiminaR, Estudios Sociales y Humanísticos, diciembre, año 8, vol. VIII, núm. 2, pp. 29-45.

Kauffer Michel, Edith F. (2011), "Agua y territorio en la cuenca binacional del río Suchiate: apropiaciones encontradas de un espacio sujeto a inundaciones", en Edith F. Kauffer Michel (coord.), Entremanantialesyríos desatados:paradojas de las hidropoliticas fronterizas (MéxicoGuatemala), México: Centro de Investigaciones y Estudios Superiores en Antropología Social/El Colegio de Michoacán, pp. 111-143.

Ortega Muñoz, Allan (2012), Una frontera en movimiento. Migración, fecundidad e identidad en el sur de Quintana Roo y norte de Honduras Británica (Belice), 1900-1935, México: Instituto Nacional de Antropología e Historia/El Colegio de México.

Pounds, Norman J. G. (1951), "The Origin of the Idea of Natural Frontiers in France", en Annals of the Association of American Geographers, vol. 41, núm. 2, pp. 146-157.

Pounds, Norman J. G. (1954), "France and "Les Limites Naturelles" from the Seventeenth to the Twentieth Centuries", en Annals of the Association of American Geographers, marzo, vol. 44, núm. 1, pp. 51-62.

Raffestin, Claude (1986), "Eléments pour une théorie de la frontière”, en Diogène, vol 34, núm. 134, Université de Genève, pp. 3-21.

Rankin K.J.y R. Schofield (2004), The troubledhistoriography of classical boundary terminology, Dublín: Institute for British-Irish Studies University College Dublin.

Santacruz de León, Germán (2011), "Problemática ambiental y conflictos sociales en torno al uso del agua en la cuenca del río Suchiate", en Edith F. Kauffer Michel (coord.), Entre manantiales y ríos 
desatados:paradojas de las hidropolíticas fronterizas (MéxicoGuatemala), México: Centro de Investigaciones y Estudios Superiores en Antropología Social/El Colegio de Michoacán, pp. 35-58.

Schaffter, Marius, Juliet Fall y Bernard Debarbieux, Bernard (2010), "Unbounded boundary studies and collapsed categories: rethinking spatial objects", en Progress in Human Geography, vol 34, núm. 2, pp. 254-262.
Turner, Frederick Jackson (1793), The Significance or the frontier in American History, 〈http://books.google.com/ books?id=v3xQXAg0PdUC\&printsec=frontcover $\&$ $\mathrm{hl}=\mathrm{es} \&$ source $=\mathrm{gbs} \_\mathrm{atb} \not \mathrm{v}=$ =nepage $\& q \& \& \mathrm{f}=\mathrm{false}>[8 \mathrm{de}$ enero de 2011]

Weber, Serge (2011), "Les frontières" en Gérardot y Philippe Lemarchan (eds.), Géographie des conflits, París: Atlande, pp. 116-120. 